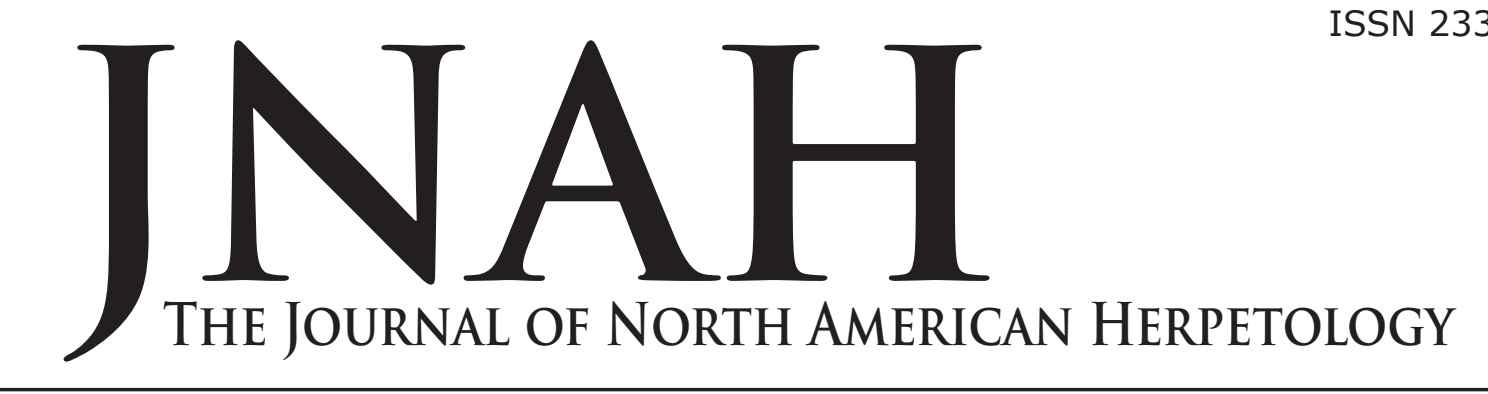

Volume 2014(1): 93-97

2 July 2014

jnah.cnah.org

\title{
COLONIZATION OF NORTHERN LOUISIANA BY THE MEDITERRANEAN GECKO, HEMIDACTYLUS TURCICUS
}

\author{
MATTHEW L. REID ${ }^{1,2,4}$, CHARLES D. BATTAGLIA ${ }^{1}$, \\ CHRIS L. RICE ${ }^{1,3}$, AND JOHN L. CARR ${ }^{1}$ \\ ${ }^{1}$ Department of Biology and Museum of Natural History, University of Louisiana at Monroe, 700 Univer- \\ sity Ave., Monroe, LA, USA 71209 \\ ${ }^{2}$ Current Address: Department of Biology, University of Louisville, Louisville, KY 40292 \\ ${ }^{3}$ Current Address: The Nature Conservancy of Louisiana, P.O. Box 4125, Baton Rouge, LA 70821 \\ ${ }^{4}$ Corresponding Author: matthew.reid.1@louisville.edu
}

\begin{abstract}
The Mediterranean Gecko, Hemidactylus turcicus, is known to have colonized nearly every state in the southern United States. In Louisiana, the Mediterranean Gecko has been documented in many of the southern parishes, but records for the northern portion of the state are limited. We sampled northern Louisiana parishes to document the presence of the Mediterranean Gecko. We sampled a total of 21 parishes in northern Louisiana and found geckos in 17 of those parishes, 16 of which represent new distribution records for the species. This indicates a significant range expansion of this introduced species throughout northern Louisiana. Geckos were found across a temperature range of $14.0-28.0^{\circ} \mathrm{C}$ and had a strong association with buildings. The species' affinity for anthropogenic association and the continual nature of anthropogenic expansion facilitate the high vagility of this species. The result is a successful colonization throughout much of Louisiana and likely continued range expansion throughout the southern United States.
\end{abstract}

Key Words._Hemidactylus turcicus; introduced species; Louisiana; Mediterranean Gecko

\section{INTRODUCTION}

Gekkonidae is a cosmopolitan family of lizards found predominantly in the tropics and warm temperate regions. Hemidactylus turcicus, the Mediterranean Gecko, is native to the Mediterranean regions of Africa, Asia, and Europe (Rose and Barbour 1968). Individuals inhabit rocky outcrops in their native range and are crepuscular to nocturnal (Rose and Barbour 1968; Arnold and Burton 1978). The species has high survivorship, calcareous eggs, small body size, and high population densities that aid in their colonization of new habitats (Selcer 1986). They are often found around man-made structures, predominantly on brick and concrete, and they are likely easily transported by anthropogenic dispersal (Rose and Barbour 1968).

Hemidactylus turcicus was first documented in the United States in Key West, Florida in 1910 (Fowler 1915); since then the species has been documented as far west as California and as far north as Utah, Illinois, and Maryland (McCoy 1970; Robinson and Romack 1973; Kraus 2012). This species has been recorded in every Gulf Coast state including Louisiana (Dundee and Rossman 1989; Conant and Collins 1998; Meshaka et al. 2006). Hemidactylus turcicus is thought to have been introduced into Louisiana first in the late 1940's by trade along the Mississippi River (Etheridge 1952; Viosca 1957) and was first reported from Ouachita Parish in 1992 (Jenson and George 1993). It has now been reported in numerous locations throughout Louisiana (Dundee and Rossman 1989; Boundy 1994, 2004; Meshaka et al. 2006; Boundy and Gregory 2012), but there are few distribution records for the northern portion of the state (Jenson and George 1993; Boundy 1994; Ray and Cochran 1997; Hardy et al. 2005; Walls 2008).

Throughout its introduced range, $H$. turcicus has been found to be highly associated with human habitations (Conant and Collins 1998). Observations suggest that geckos prefer substrates similar to their native habitats, i.e., rough outer surfaces such as brick, cement, and wood (Paulissen and Buchanan 1991; Meshaka et al. 2006; Jaden and Coleman 2007). Other reports include use of sidewalks, construction material, and trees (Meshaka et al. 2006). Individuals have been documented in well-lit areas, but seem to prefer areas with indirect light (Paulissen and Buchanan 1991; Nelson and Carey 
1993; Meshaka et al. 2006). Although this species prefers warm temperatures, individuals have been found to be active at temperatures as low as $3.3^{\circ} \mathrm{C}$ (Rose and Barbour 1968; Dundee and Rossman 1989).

The main objective of our study was to document the extent of the colonization of the Mediterranean Gecko in northern Louisiana parishes. Our second objective was to record habitat characteristics for locations where geckos were found.

\section{MATERIALS AND METHODS}

We sampled locations throughout northern Louisiana from 2008 to 2012. We focused our collection efforts along major highways and in urban areas. Major highways have a high volume of vehicular traffic to transport geckos and larger cities and towns have more suitable habitat. We sampled gasoline stations, grocery stores, and shopping plazas most often. These areas often receive shipments by truck, which are likely good vectors of dispersal for this species (Davis 1974). Additionally, we more intensively sampled Ouachita Parish in order to document the extent of range expansion within the most populous parish in northeastern Louisiana.

Sampling typically occurred between sunset and midnight. Geckos were detected using flashlights. Upon detection, we counted the number of geckos in the area. We then attempted to capture at least one gecko per site, using the hand capture technique. Ambient temperature, relative humidity, substrate, and light conditions were also recorded for each capture. Upon successful capture, we collected geographic coordinates for mapping purposes with a GPS receiver (NAD83 map datum). We retained at least one specimen for each parish in which geckos were not previously collected. All geckos were humanely euthanized and deposited in the University of Louisiana at Monroe Museum of Natural History. Maps were created in ArcMap.

\section{Distribution}

\section{RESULTS}

We sampled in 21 parishes and found 80 geckos in 17 of those parishes, including Bienville (1), Bossier (1), Caldwell (2), Catahoula (1), Concordia (1), Franklin (1), Jackson (3), Lincoln (1), Madison (1), Morehouse

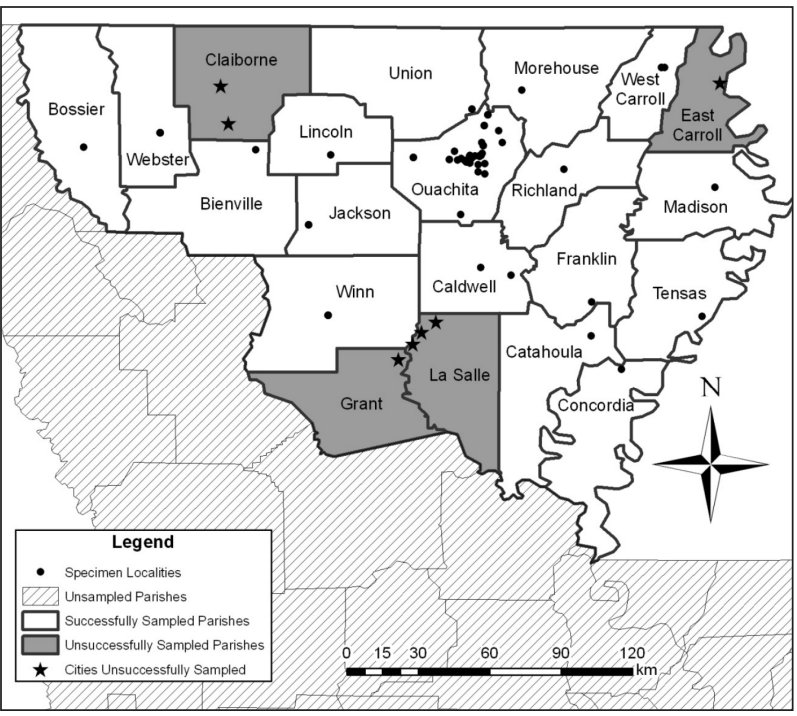

Figure 1. Map of northern Louisiana showing sampling locations for the Mediterranean Gecko (Hemidactylus turcicus).
(2), Ouachita (44), Richland (3), Tensas (1), Union (3), Webster (6), West Carroll (3), and Winn (6) (Figure 1 , Appendix 1). We sampled four other parishes (Claiborne, East Carroll, Grant, and La Salle), but were unsuccessful in locating geckos.

In Ouachita Parish, we recorded 44 geckos from 29 localities (Figure 2). We were able to obtain a specimen from every city or town that was sampled. Other specimens were obtained from unincorporated portions of Ouachita Parish and our collection records were supplemented by reliable sightings.

Environmental Variables

We observed geckos at temperatures ranging from $14.0-28.0^{\circ} \mathrm{C}$, with an average temperature of $25.0^{\circ} \mathrm{C}$ \pm 2.4 (SD). Geckos were found at relative humidities of $56-67 \%$, with an average of $63 \% \pm 3.2$ (SD). We found the majority of the geckos on rough surfaces such as brick (37) and cinderblock (26). We found geckos on other substrates, although to a lesser degree. Other rough surfaces on which geckos were found included cement/stucco (4), wood (3), and concrete sidewalks (3). We did encounter a few geckos on smooth surfaces such as metal (2), tile (1), and glass (1). Other geckos included one indoors associated with a cardboard box, one in a plastic pot, and one trapped in a stored funnel trap in a metal building (Figure 3 ). Of the geckos encountered, all were on or in a building, except for the three on sidewalks near buildings and the one in a plastic pot.

We found geckos in a variety of light environments ranging from complete darkness to areas of indirect light. Two geckos were observed during daylight hours. Likewise, we observed geckos in a range of proximity to light. Half of the geckos (29 of 58) for which light data were collected were found at distances greater than 20 $\mathrm{m}$ from the nearest light source (Figure 4), while 10 (of 58 ) others were found at distances of less than $10 \mathrm{~m}$ from the nearest light source. Often we observed geckos around the corners of buildings; these geckos were

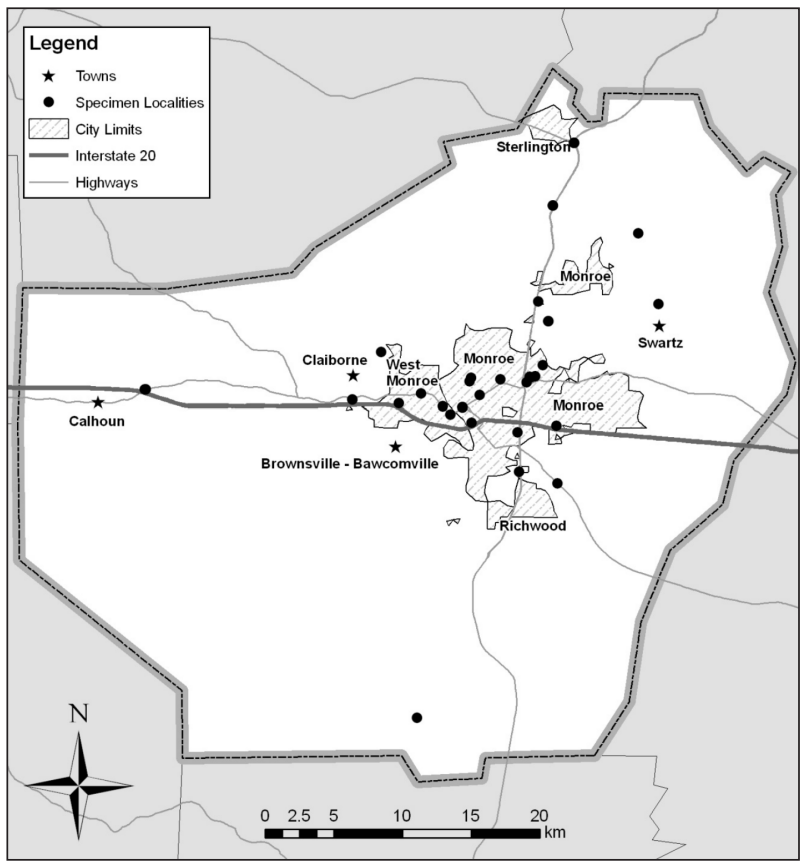

Figure 2. Map of Ouachita Parish showing locations where Mediterranean Geckos (Hemidactylus turcicus) were found. 
in close proximity to light and yet remained in the dark based on the direction of the light.

\section{DISCUSSION}

As a result of this study, we have documented 16 new parish records for Hemidactylus turcicus in Louisiana (Figure 1). This indicates a significant colonization of $H$. turcicus throughout most of northern Louisiana. Meshaka et al. (2006) included a report of $H$. turcicus in Webster Parish, but we now have a museum specimen to document the species presence. We were unsuccessful in obtaining a specimen in four parishes (Claiborne, East Carroll, Grant, La Salle). We visited the largest cities in Claiborne and East Carroll Parishes but were unable to sample the largest cities in Grant and La Salle Parishes due to time constraints. In Ouachita Parish, we were successful in locating geckos throughout much of the parish, in both urban and suburban areas (Figure 2 ). Often when we sampled unincorporated areas we were unsuccessful in obtaining specimens, which could be the result of reduced human traffic. It is possible that geckos are present in these areas but were simply undetected; this is especially true in Grant and La Salle Parishes where sampling was not done in the largest cities. Thus, these distributional gaps may reflect an absence of sufficient effort rather than an absence of geckos (Farallo et al. 2009).

All but one of the geckos observed were in urban or suburban areas, and that gecko was found at Boeuf Wildlife Management Area in Caldwell Parish. We collected specimens from the majority of parishes by sampling areas of high human traffic along major roadways, supporting the claim that transportation along these roadways provides a means of dispersal for this species. We observed $H$. turcicus eggs in multiple cardboard boxes used for packing and shipping, which may be readily transported via trucking routes (Davis 1974) or other means of transportation. This may contribute to the high vagility of this species, leading to frequent jump dispersal events (Locey and Stone 2006). Such dispersal from the early Ouachita Parish colony is likely responsible for the successful establishment of $H$. turcicus throughout northeastern Louisiana. The Ouachita Parish population may also serve as a source of dispersal into Arkansas.

We observed geckos active over a wide range of temperatures, which is consistent with previous research

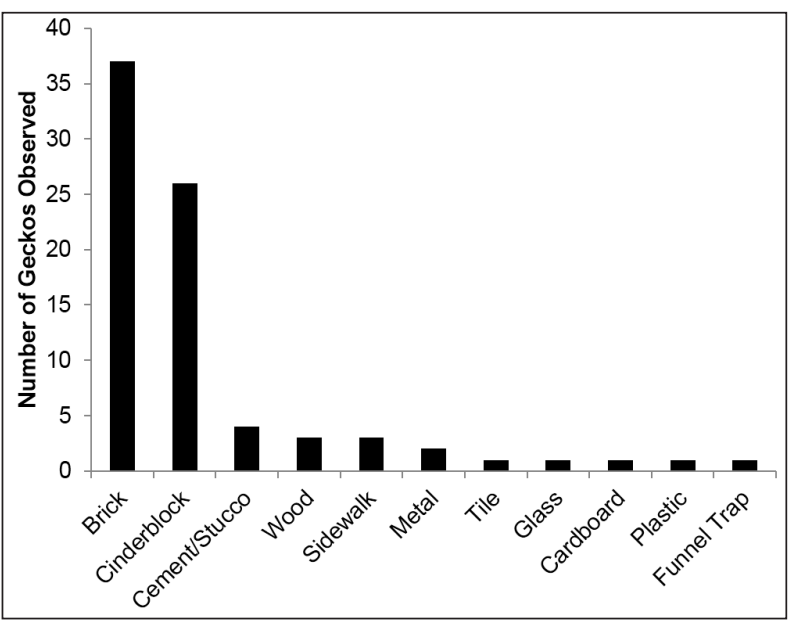

Figure 3. Number of geckos observed based on substrate. Note that there was not equal sampling among substrates.
(Rose and Barbour 1968). The range of relative humidity in which geckos were observed to be active was narrow, but this is likely the result of the consistently high humidity that characterizes northern Louisiana. While our sampling was not equal among the substrate types, we found the majority of the geckos on rough, vertical surfaces, similar to results reported by Meshaka et al. (2006). We also found a few geckos on smooth surfaces such as metal and glass. This was unexpected, since use of smooth-textured substrates has not been largely reported in the literature. The use of rough substrates likely reflects the preference to select substrates similar to habitat in its native range (Meshaka et al. 2006; Jadin and Coleman 2007).

The majority of the geckos we observed were found in lighting classified as minimal to none, while a few were found in indirect light. We did not observe geckos in well-lit areas, indicating a preference for low-light. Many of the observed geckos were found to be greater than $20 \mathrm{~m}$ from the nearest light source. It is important to note that geckos found in closer proximity to light sources were never in direct light. Although light may provide a benefit by attracting potential insect prey, it may also expose them to potential predators such as spiders, birds, and cats (Punzo 2001). In addition, we encountered geckos in areas lacking any light sources, as previously observed by Nelson and Carey (1993) and Meshaka et al. (2006).

Introduced species often have negative impacts on the native flora and fauna, as well as causing severe economic impacts (Pimentel et al., 2005), but there seem to be no clearly demonstrated negative impacts of Hemidactylus turcicus on native species. However, Punzo (2005) suggested that $H$. turcicus might reduce populations of native nocturnal wolf and crab spiders. The topic of potential competition for similar prey between $H$. turcicus and hylid treefrogs remains unresolved (Meshaka et al. 2006). In our study, $H$. turcicus and hylid treefrogs were often encountered on the same buildings and thus could be competing for shared resources. To our knowledge, no other potentially negative impacts have been suggested. It is possible that humans could receive a positive benefit from this species since $H$. turcicus is a predator of many insect pests (Locey and Stone 2006; Civantos et al. 2012).

Although Hemidactylus turcicus is introduced in Louisiana, this species currently seems to lack the negative

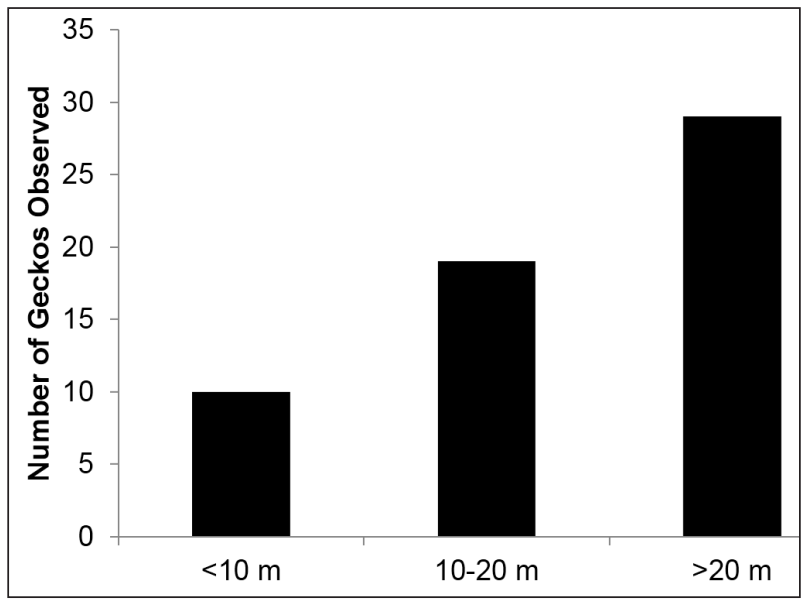

Figure 4. Number of geckos observed based on distance to light source. Note that there was not equal sampling among groups. 
stigma associated with introduced species. In fact, this species was often viewed favorably and with interest by the people we encountered during periods of sampling. This absence of a negative stigma results in a lack of desire to limit the dispersal of this species. The affinity of this species for anthropogenic habitat and the continual nature of anthropogenic expansion and transport of cargo facilitate the high vagility of this species. The result is a wide distribution in Louisiana and likely continued range expansion throughout the southern United States.

\section{ACKNOWLEDGMENTS}

We thank Kody Chase, Clayton Faidley, Chase Holliday, Justin Martin, Sarah Rhoads, Nora Smith, and Jessica Wakefield for assistance collecting geckos. We also thank the many friendly business owners who let us search their property for geckos. All geckos were collected under Louisiana Natural Heritage Program permits \#08-043 and \#12-049 and Louisiana Department of Wildlife and Fisheries permit \#WL-Research-2012-05.

\section{LITERATURE CITED}

Arnold, E.N., and J.A. Burton. 1978. A Field Guide to the Reptiles and Amphibians of Britain and Europe. Collins, London, United Kingdom.

Boundy, J. 1994. Range extensions for Louisiana amphibians and reptiles. Herpetological Review 25:128-129.

Boundy, J. 2004. Amphibian and reptile distribution records for Louisiana. Herpetological Review 35:194196.

Boundy, J., and B. Gregory. 2012. Amphibian and reptile distribution records for Louisiana - II. Herpetological Review 43:113-114.

Civantos, E., W. Thuiller, L. Maiorano, A. Guisan, and M.B. Araújo. 2012. Potential impacts of climate change on ecosystem services in Europe: the case of pest control by vertebrates. BioScience 62:658666.

Conant, R., and J.T. Collins. 1998. A Field Guide to Reptiles and Amphibians of Eastern and Central North America, $3^{\text {rd }}$ edition expanded. Houghton Mifflin Company, Boston, Massachusetts, USA.

Davis, W.K. 1974. The Mediterranean Gecko, Hemidactylus turcicus in Texas. Journal of Herpetology 8:77-80.

Dundee, H.A., and D.A. Rossman. 1989. The Amphibians and Reptiles of Louisiana. Louisiana State University Press, Baton Rouge, Louisiana, USA.

Etheridge, R.E. 1952. The Warty Gecko, Hemidactylus turcicus (Linnaeus), in New Orleans, Louisiana. Copeia 1952:47-48.

Farallo, V.R., R.L. Swanson, G.R. Hood, J.R. Troy, and M.R.J. Forstner. 2009. New county records for the Mediterranean House Gecko (Hemidactylus turcicus) in central Texas, with comments on human-mediated dispersal. Applied Herpetology 6:196-198.

Fowler, H.W. 1915. Cold-blooded vertebrates from Flori$\mathrm{da}$, the West Indies, Costa Rica, and eastern Brazil. Proceedings of the Academy of Natural Sciences of Philadelphia 67:244-269.

Hardy, L.M., A.C. Crnkovic, and L.R. Raymond. 2005. Geographic distribution: Hemidactylus turcicus (Mediterranean House Gecko). Herpetological Review 36:201-202.
Jadin, R.C., and J.L. Coleman. 2007. New county records of the Mediterranean House Gecko (Hemidactylus turcicus) in northeastern Texas, with comments on range expansion. Applied Herpetology 4:90-94.

Jenson, S.L., and S.G. George. 1993. Geographic distribution: Hemidactylus turcicus (Mediterranean Gecko). Herpetological Review 24:154.

Kraus, F. 2012. Alien species. Pp. 82-92 In Scientific and Standard English and French Names of Amphibians and Reptiles of North America North of Mexico, with Comments Regarding Confidence in our Understanding, $7^{\text {th }}$ edition. Crother, B.I. (Ed.). SSAR Herpetological Circular 39:1-92.

Locey, K.J., and P.A. Stone. 2006. Factors affecting range expansion in the introduced Mediterranean Gecko, Hemidactylus turcicus. Journal of Herpetology 40:526-530.

McCoy, C.J. 1970. Hemidactylus turcicus (Linnaeus), Mediterranean Gecko. Catalogue of American Amphibians and Reptiles 87:1-2.

Meshaka, W.E., Jr., S.D. Marshall, J. Boundy, and A.A. Williams. 2006. Status and geographic expansion of the Mediterranean Gecko, Hemidactylus turcicus, in Louisiana: implications for the southeastern United States. Herpetological Conservation and Biology $1: 45-50$.

Nelson, D., and S. Carey. 1993. Range extensions of the Mediterranean Gecko (Hemidactylus turcicus) along the northeastern Gulf coast of the United States. Northeast Gulf Science 13:53-58.

Paulissen, M.A., and T.M. Buchanan. 1991. Observations on the natural history of the Mediterranean Gecko, Hemidactylus turcicus (Sauria; Gekkonidae) in northwestern Arkansas. Proceedings of the Arkansas Academy of Science 45:81-83.

Pimentel, D., R. Zuniga, and D. Morrison. 2005. Update on the environmental and economic costs associated with alien-invasive species in the United States. Ecological Economics 52:273-288.

Punzo, F. 2001. The Mediterranean Gecko (Hemidactylus turcicus): life in an urban landscape. Florida Scientist 64:56-66.

Punzo, F. 2005. The introduction of hemidactyline geckos in Florida: colonization and impact on native fauna. Pp. 231-237 In Amphibians and Reptiles: Status and Conservation in Florida. Meshaka, W.E., Jr., and K.J. Babbitt (Eds.). Krieger Publishing Company, Malabar, Florida, USA.

Ray, J., and B. Cochran. 1997. Geographic distribution: Hemidactylus turcicus (Mediterranean Gecko). Herpetological Review 28:157.

Robinson, M.D., and C.W. Romack. 1973. The Mediterranean Gecko (Hemidactylus turcicus), a species new to the herpetofauna of Arizona. Journal of Herpetology 7:311-312.

Rose, F.L., and C.D. Barbour. 1968. Ecology and reproductive cycles of the introduced gecko, HemidactyIus turcicus, in the southern United States. American Midland Naturalist 79:159-168.

Selcer, K.W. 1986. Life history of a successful colonizer: the Mediterranean Gecko, Hemidactylus turcicus, in southern Texas. Copeia 1986:956-962.

Viosca, P., Jr. 1957. Have you a little gecko in your home? Louisiana Conservationist 9:20-21.

Walls, J.G. 2008. Geographic distribution: Hemidactylus turcicus (Mediterranean Gecko). Herpetological Review 39:367. 
Appendix 1. Specimens Examined

HEMIDACTYLUS TURCICUS (Mediterranean Gecko). NAD83.

Bienville Parish:

2199 Beech St., Arcadia (32.55088N, 92.92341W). 1 May 2012. NLU 70702.

Bossier Parish:

770 Randy Ln., Haughton (32.55992N, 93.57333W). 11 March 2012. NLU 70694.

Caldwell Parish:

Intersection of Main St. and Levee St., Columbia (32.10638 $\left.{ }^{\circ} \mathrm{N}, 92.07437^{\circ} \mathrm{W}\right) .29$ April 2008. NLU 70685; Boeuf Wildlife Management Area (32.07659N, $\left.91.95945^{\circ} \mathrm{W}\right) .13$ May 2012. NLU 70706.

Catahoula Parish: Intersection of Highway 15 and Highway 8, Sicily Island (31.84721 $\left.\mathrm{N}, 91.65761^{\circ} \mathrm{W}\right) .28$ April 2012. NLU 70700 .

Concordia Parish:

Intersection of Highway 566 and Highway 15, Clayton (31.72205 N, 91.54338 $\mathrm{W}) .24$ March 2012. NLU 70689.

Franklin Parish:

9660 Natchez St., Wisner (31.97631N, 91.65537ºW). 28 April 2012. NLU 70698.

Jackson Parish:

On Highway 147 near intersection with Highway 813, Hodge (32.26699 $\left.\mathrm{N}, 92.72428^{\circ} \mathrm{W}\right) .4 \mathrm{May} 2012 . \mathrm{NLU}$ 70704.

Lincoln Parish:

211 N. Trenton St., Ruston (32.53005N, 92.63941W). 22 April 2008. NLU 70684.

Madison Parish:

Intersection of Snyder St. and N. Walnut St., Tallulah $\left(32.40839^{\circ} \mathrm{N}, 91.18894^{\circ} \mathrm{W}\right) .8$ July 2008. NLU 70686.

Morehouse Parish:

323 W. Walnut Ave., Bastrop (32.77433N, 91.91776W). 22 April 2008. NLU $70679 \& 70680$.

Ouachita Parish:

985 Highway 80 E., Calhoun (32.52055N, 92.32802W). 12 March 2012. NLU 70697; 3980 Old Sterlington Rd., Monroe $\left(32.56514^{\circ} \mathrm{N}, 92.06431^{\circ} \mathrm{W}\right) .2$ March 2012. NLU 70693; 8635 Highway 165 N., Monroe $\left(32.64082^{\circ} \mathrm{N}\right.$, 92.06106 ${ }^{\circ}$ W). 16 March 2012. NLU 70692; Intersection of University Ave. and Northeast Dr., Monroe $\left(32.52895^{\circ} \mathrm{N}\right.$, 92.07623W). 27 March 2012. NLU 70691; 3980 Old Sterlington Rd., Monroe $\left(32.56514^{\circ} \mathrm{N}, 9^{\circ} .06431^{\circ} \mathrm{W}\right) .2$ May 2012. NLU 70699; 3421 Medical Park Dr., Monroe (32.57816N, $\left.92.07075^{\circ} \mathrm{W}\right) .8$ April 2008. NLU 70678; 309 Jackson St., Monroe $\left(32.49914^{\circ} \mathrm{N}, 92.11454^{\circ} \mathrm{W}\right) .8$ April 2008. NLU 70674; 510 Warhawk Way, Monroe $\left(32.53537^{\circ} \mathrm{N}, 92.06601^{\circ} \mathrm{W}\right) .14$ March 2012 . NLU 70690; $1900 \mathrm{~N} .18^{\text {th }}$ St., Monroe $\left(32.52824^{\circ} \mathrm{N}, 92.11458^{\circ} \mathrm{W}\right)$. 8 April 2008. NLU 70675 \& $70676 ; 1801$ N. $18^{\text {th }}$ St., Monroe $\left(32.52669^{\circ} \mathrm{N}, 92.11561^{\circ} \mathrm{W}\right) .8$ April 2008. NLU 70677; 1333 Highway 2, Sterlington (32.68189 N, 92.04743ㅇ). 16 March 2012. NLU 70695 \& $70705 ; 113$ Topic St., Swartz $\left(32.62265^{\circ} \mathrm{N}, 92.00531^{\circ} \mathrm{W}\right) .28$ July 2012. NLU 70708; 220 Blanchard St., West Monroe $\left(32.51176^{\circ} \mathrm{N}, 92.16202^{\circ} \mathrm{W}\right) .8$ April 2008. NLU 70672 \& 70673.

Richland Parish:

112 Morgan St., Rayville (32.47584N, 91.76026º W). 22 April 2008. NLU 70681, 70682 \& 70683.

Tensas Parish:

705 Plank Rd., St. Joseph (31.92121N, 91.23817ºW). 24 March 2012. NLU 70696.

Union Parish:

On Highway 2 near intersection with Parish Rd. 8848, (32.70317º , 92.10610W). 28 July 2012. NLU 70707.

Webster Parish:

138 E. Union St., Minden (32.61439N, 93.28462 W). 1 May 2012. NLU 70703.

West Carroll Parish: On Highway 2 near intersection with Highway 17, Oak Grove $\left(32.86118^{\circ} \mathrm{N}, 91.39122^{\circ} \mathrm{W}\right) .29$ March 2012. NLU 70687; 803 E. Main St., Oak Grove (32.86018N, 91.37954W). 29 March 2012. NLU 70688.

Winn Parish: On Highway 84 near intersection with Highway 167, Winnfield (31.92520N, 92.64988W). 4 May 2012. NLU 70701. 